\author{
Hossein Saghi ${ }^{1}$, Abbas Bahador ${ }^{2}$, \\ Ferdoes Amiri Dastjerdi ${ }^{1}$, Hassan \\ Asadolahi ${ }^{1}$, Mehdi Neyshaboori ${ }^{1}$, \\ Esmaeili Mohammad ${ }^{3}$, Meskini \\ Maryam $^{3}$ and Davoud Esmaeili ${ }^{3 *}$ \\ ${ }^{1}$ AJA University of Medical Sciences, Tehran, IR Iran \\ ${ }^{2}$ Department of Medical Microbiology, Tehran \\ University of Medical Sciences, Iran \\ ${ }^{3}$ Microbiology Department Baqiyatallah University \\ Medical of Sciences, Iran
}

Dates: Received: 21 September, 2015; Accepted: 26 October, 2015; Published: 28 October, 2015

${ }^{*}$ Corresponding author: Davoud Esmaeili, Department of Microbiology, Baqiyatallah University of Medical Sciences, Tehran, IR Iran. Tel: +989124395884; Fax: +98-2177601533; E-mail: esm114@gmail.com

www.peertechz.com

ISSN: 2455-5363

Keywords: Acinetobacter baumannii; Antibacterial Effects; Multidrug-resistant; Satureja essence; MIC

\author{
Research Article
}

\section{Antibacterial Effects of Herbal Compounds against Acinetobacter baumannii Isolated from Hospital of Tehran, Iran}

\section{Introduction}

Acinetobacter baumannii is a gram-negative bacteria and important opportunistic pathogen, causes a variety of nosocomial infections especially in Intensive Care Units (ICU's) [1,2]. These infections include bacteremia, surgical-site infections, secondary meningitis, urinary tract infections and ventilator associated pneumonia. These organisms have been implicated in a diverse range of infections such as respiratory tract, blood stream, skin and soft tissue. The rapid emergence and global dissemination of A. baumannii as a major nosocomial pathogen is remarkable and demonstrates its successful adaptation to the 21st century hospital environments [3]. Use of medicinal herbaceous drugs recommended for treatment since ancient periods. Humans have been used and realize their beneficial effects. With the increase in population and urban growth, and reduced use of synthetic drugs, many of these of medicinal herbs have been replaced [4]. The usage problems such as the increasing resistance of microorganisms and reduce the impact of the continuing application is reported.

\section{Materials and Methods}

\section{Extraction, isolation and identification of the oils}

Aerial parts of Satureja and Thyme were collected from Barij Essence research farm in May 2010. Plant material and extraction procedure flowering aerial parts of $O$. vulgare was collected from Khoramabad, Lorestan, Iran, in June 2010. Essential oils by steam distillation of the aerial parts of the plant were prepared aerial. Oil after drying with sodium sulfate at $4^{\circ} \mathrm{C}$ until the GC (gas chromatography) injection system was kept. Analysis and identification of constituent composition of the oils was performed by Barij Essence Company. The fresh flowering aerial parts of Satureja, Origanum vulgare and Thyme were subjected to hydro distillation and a yield of $0.27 \%(\mathrm{v} / \mathrm{w})$ was obtained. The GC /MS (gas chromatography-mass spectrometer) results indicated that these oils have many antibacterial compounds. The GC apparatus was Agilent technology (HP) 6890 system, capillary column of HP-5MS $\left(60 \mathrm{~m} \times 0.25 \mathrm{~mm}\right.$, film thickness $\left.0.25 \_\mathrm{m}\right)$. The oven temperature program was initiated at $40^{\circ} \mathrm{C}$, held for $1 \mathrm{~min}$ then raised up to $230^{\circ} \mathrm{C}$ at a rate of $3^{\circ} \mathrm{C} / \mathrm{min}$ held for $10 \mathrm{~min}$. Helium was used as the carrier gas at a flow rate $1.0 \mathrm{ml} / \mathrm{min}$.

\section{Bacterial strain and culture conditions}

The number of seventy five Acinetobacter baumannii strains was isolated and identified using standard microbiological methods. Susceptibility testing of antibiotics neomycin, gentamicin, amikacin, kanamycin, imipenem and oxacillin were performed. The resistant strains were used to investigate in order to antimicrobial effect of Satureja, Origanum vulgare and Thyme essence. To evaluate the antimicrobial effects Satureja, Origanum vulgare and Thyme essential oil diffusion method (disk diffusion) were used. We use dimethyl sulfoxide (DMSO) for dissolve essential oil. Culture carried out with sterile swab and micro tube suspension was cultured for $24 \mathrm{~h}$ and then inoculated onto Mueller Hinton agar. Blank discs with a diameter of $6 \mathrm{~mm}$ and containing $30 \mu \mathrm{l}$ of the concentration of essential oils were placed on Muller Hinton agar medium. After 24 $\mathrm{h}$ incubation at $37^{\circ} \mathrm{C}$, zones of growth inhibition were measured. Each concentration was repeated 3 times for each of the bacteria and 
the average was documented. Disks containing $30 \mu \mathrm{l}$ of dimethyl sulfoxide were used as a negative control. To determine the minimum inhibitory concentration (MIC) for the Satureja, Origanum vulgare and Thyme essential oil to $100 \mu \mathrm{l}(100 \%$ concentration) was dissolved in $900 \mu \mathrm{l} \mathrm{DMSO}$. Then the $1,2,3,4,5,6,7,8,9,10 \mu \mathrm{g}$ of this suspension was added to $1 \mathrm{ml}$ Muller Hinton broth. After mixing, $1 \mathrm{ml}$ of bacterial suspension $\left(1.5 \times 10^{8} \mathrm{cfu} / \mathrm{ml}\right)$ was added to the medium after incubation at $37^{\circ} \mathrm{C}$ for $24 \mathrm{~h}$ and the results were evaluated. Acinetobacter baumannii ATCC 19606 was employed in this study as a model reference strain.

\section{Results and Discussion}

Antibiotic susceptibility test results the number of seventy five Acinetobacter baumannii strains are as follows. Oxacillin (100\%), Amikacin (75\%), Kanamycin (68\%), Gentamicin (60\%), Imipenem $(60 \%)$ and $(89 \%)$ were resistant Neomycin. Inhibitory effects of Satureja on drug-resistant strains were found. Results MIC $(\mu \mathrm{g} / \mathrm{ml})$ Satureja, Origanum vulgare and Thyme essential oils and Zone of growth inhibition $(\mathrm{mm})$ pathogen strain Acinetobacter baumannii (Table 1) (Figure 1). The major components of Satureja essence were carvacrol (90.88\%), $\rho$-cymene (3.11\%), $\gamma$ - trepanned (1.24\%), linalool (0.91\%), Origanum vulgare are Pulegone (68.59\%), Piperitenone Oxide and Piperitone (7.8\%) and the Thyme are thymol (28.8\%) and carvacrol (23.46\%).

\section{Conclusions}

Nosocomial infections caused by Multidrug resistant strains of Acinetobacter baumannii (MDR-AB) are currently among the most difficult to treat, and they continue to present serious challenges to clinicians' empirical and therapeutic decisions in burned patient [5]. Outbreaks of extensively, and pan drug-resistant A. baumannii (XDR, and PDR, respectively) currently has been reported from worldwide.

Table 1: Results MIC Satureja, Origanum vulgare and Thyme essential oils the standard strain and Pathogen strain A. baumannii.

\begin{tabular}{|c|c|c|c|}
\hline \multicolumn{2}{|l|}{ Pathogenic strains } & \multirow{2}{*}{$\begin{array}{l}\begin{array}{l}\text { Acinetobacter } \\
\text { baumannii }\end{array} \\
0.3 \\
\end{array}$} & \multirow{2}{*}{$\begin{array}{l}\text { A.baumannii } \\
\text { ATCC } 19606 \\
0.5\end{array}$} \\
\hline \multirow{3}{*}{$\begin{array}{l}\text { Satureja } \\
\text { Essence }\end{array}$} & Average MIC $(\mu \mathrm{g} / \mathrm{ml})$ & & \\
\hline & Average MBC $(\mu \mathrm{g} / \mathrm{ml})$ & 0.48 & 0.7 \\
\hline & $\begin{array}{l}\text { Average Zone of growth } \\
\text { inhibition }(\mathrm{mm})\end{array}$ & 25.5 & 24 \\
\hline \multirow{3}{*}{ Origanum vulgare } & Average MIC $(\mu \mathrm{g} / \mathrm{ml})$ & 2.6 & 2.5 \\
\hline & Average MBC $(\mu \mathrm{g} / \mathrm{ml})$ & 3.2 & 3 \\
\hline & $\begin{array}{l}\text { Average Zone of growth } \\
\text { inhibition }(\mathrm{mm})\end{array}$ & 10.8 & 15 \\
\hline \multirow{3}{*}{$\begin{array}{l}\text { Thyme } \\
\text { Essence }\end{array}$} & Average $\mathrm{MIC}(\mu \mathrm{g} / \mathrm{ml})$ & 0.44 & 0.5 \\
\hline & Average MBC $(\mu \mathrm{g} / \mathrm{ml})$ & 0.6 & 0.7 \\
\hline & $\begin{array}{l}\text { Average Zone of growth } \\
\text { inhibition }(\mathrm{mm})\end{array}$ & 18.6 & 24 \\
\hline \multirow{3}{*}{$\mathrm{MIC}(\mu \mathrm{g} / \mathrm{ml})$} & CIP & $>4$ & $>4$ \\
\hline & GM/IMP & $>16$ & $>16$ \\
\hline & AMK/CRO/OX/K/N & $>64$ & $>64$ \\
\hline \multirow{3}{*}{$\begin{array}{l}\text { Zone of growth } \\
\text { inhibition(mm) }\end{array}$} & CIP & 0 & 0 \\
\hline & GM/IMP & 0 & 0 \\
\hline & AMK/CRO/OX/K/N & 0 & 0 \\
\hline
\end{tabular}

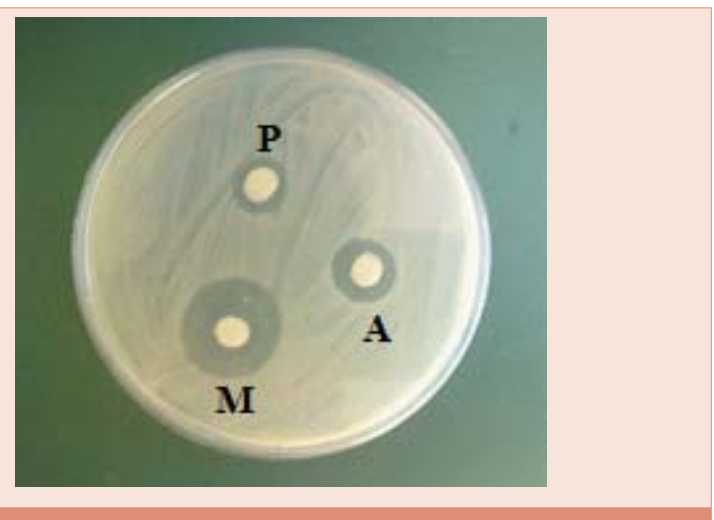

Figure 1: Zone of Growth Inhibition of the Satureja, Origanum vulgare and Thyme essence against Multidrug-Resistant Acinetobacter baumannii .M (Satureja), A (Thyme), P (Origanum vulgare).

Health problems have been caused by Acinetobacter spp. and the possibility of transition between living and nonliving things as well as long-term survival in hospital environments enhance the appearance of this bacterium in hospital environments and its consequent infections [4]. In this study, the high prevalence of XDR and PDR A. baumannii isolates ( $37.1 \%$ and $8.1 \%$, respectively) from patients is consistent with previous reports [6,7]. Increasing prevalence of XDR and PDR A. baumannii strains and limited treatment options has prompted the use of antibiotics combinations like tigecycline and colistin as therapeutic regimens $[8,9]$. There are several studies on the effects of antibacterial essential oils of Thyme and Satureja including carvacrol and thymol. The major antimicrobial properties of these plants are dependent carvacrol and thymol [10]. In the study by Kim and et al., antibacterial effects of carvacrol on Salmonella typhimurium were studied. Carvacrol had a strong antibacterial effects [11]. In a study, Satureja inhibitory effect on the enzyme S, exotoxin a, secretory systems and efflux pumps of Pseudomonas aeruginosa was investigated by semi-quantitative RT-PCR technique, against this genes has an inhibitory effects [12]. The antimicrobial essential oil of Origanum vulgare against a range of bacteria including: Staphylococcus species, Pseudomonas, Bacillus and E. coli as well as some fungal species such as Aspergillus, Fusarium and Penicillium been found [13].In this research, Satureja, Origanum vulgare and Thyme essence were used to assessment their antibacterial activity against important pathogen by inserting some minor changes to the CLSI recommended agar dilution method that have been originally developed for analyzing the conventional antimicrobial agents activity, so it could be used to analyze plant extracts and essential oils for their antimicrobial activity. Due to the high resistance to more drugs and disinfectants in A. baumannii and high prevalence of nosocomial infections and enormous economic costs and the restrictions on the use of broadspectrum drugs in persons with Immune compromised applications of native compounds against these pathogens resulted in these which can be effective enough to reduce the rate of infection transmission. According to results of current research we hope in future be used it to the clinic with a wider range as a complementary therapy. Additional clinical research and trials are necessary to completely confirm the above results for medical purposes. 


\section{References}

1. Bou G, Cervero G, Dominguez MA, Quereda C, Martinez-Beltran J (2000) Characterization of nosocomial outbreak caused by a multiresistant Acinetobacter baumannii strain with a carbapenem-hydrolyzing enzyme: high-level carbapenem resistance in A. baumannii is not due solely to the presence of ß-lactamases. J Clinic Microbe 38: 3299-3305.

2. Hanlon GW (2005) The emergence of Multidrug resistant Acinetobacter species: A major concern in the hospital setting. Lett Apple Microbial 41: 375-378.

3. Ku SC, Hsueh PR, Yang PC, Luh KT (2000) Clinical and microbiologica characteristics of bacteremia caused by Acinetobacter Iwoffii. Eur $\mathrm{J}$ Clin Microbial Infect 19: 501-505.

4. Sharififar F, Moshafi MH, Mansouri SH, Khodashenas M, Khoshnoodi M (2007) In vitro evaluation of antibacterial and antioxidant activities of the essential oil and methanol extract of endemic Zataria multiflora Boiss. Food Control 18: 800-805.

5. Yali G, Jing C, Chunjiang L, Cheng Z, Xiaoqiang L, et al. (2014) Comparison of pathogens and antibiotic resistance of burn patients in the burn ICU or in the common burn ward. Burns 40: 402-407.

6. Chang KC, Lin MF, Lin NT, Wu WJ, Kuo HY, et al. (2012) Clonal spread of multidrug-resistant Acinetobacter baumannii in eastern aiwan. J Microbiol Immunol Infect 45: 37-42.

7. Kusradze la, Diene SM, Goderdzishvili M, Rolain JM (2011) Molecula detection of OXA carbapenemase genes in multidrug-resistant Acinetobacter baumannii isolates from Iraq and Georgia. Int J Antimicrob Agents 38: 164168.

8. Safari M, Saidijam M, Bahador A, Jafari R, Alikhani MY (2013) High Prevalence of Multidrug Resistance and Metallo-beta-lactamase (M $\mathrm{BL}$ ) producing Acinetobacter baumannii Isolated from Patients in ICU Wards, Hamadan, Iran. J Res Health Sci 13: 162-167.

9. Mohamed NM, Youssef AA (2011) In vitro activity of tigecycline and comparators against gram-negative bacteria isolated from a tertiary hospita in Alexandria, Egypt. Microb Drug Resist 17: 489-495

10. Burt SA, Vlielander R, Haagsman HP, Veldhuizen EJ (2005) Haagsman. Increase in Activity of Essential Oil Components Carvacrol and Thymol against Escherichia coli O157:H7 by Addition of Food Stabilizers. J Food Prot 68: 919-926.

11. Kim E, Choi Y, Jang J, Park T (2013) Carvacrol Protects against Hepatic Steatosis in Mice Fed a High-Fat Diet by Enhancing SIRT1-AMPK Signaling. Evid Based Complement Alternat Med 290104.

12. Esmaeili D, Mobarez AM, Tohidpour A (2012) Anti-Helicobacter pylori Activities of Shoya Powder and Essential Oils of Thymus Vulgaris and Eucalyptus Globulus. Open Microbiol J 65-69.

13. Gulluce M, Sahin F, Sokmen M, Ozer H, Daferera D, et al. (2007) Antimicrobial and antioxidant properties of the essential oils and methanol extract from menthalongifolia L ssp. Longifolia. Food Chem 103: 1449-1456.

Copyright: (c) 2015 Saghi $\mathrm{H}$, et al. This is an open-access article distributed under the terms of the Creative Commons Attribution License, which permits unrestricted use, distribution, and reproduction in any medium, provided the original author and source are credited. 